\title{
Pengembangan Sistem Informasi Manajemen Sumber Daya Manusia
}

\author{
Yuni Marlina Saragih, Winda Irma Wati Br Siagian, Fandi Halim, Zulpa Salsabila \\ Program Studi Sistem Informasi, STMIK Mikroskil, Medan, Indonesia \\ Email: ${ }^{1}$ yuni.saragih@mikroskil.ac.id, ${ }^{2}$ windairmawati96@gmail.com, ${ }^{3}$ fandi@ mikroskil.ac.id, \\ ${ }^{4}$ zulpa.salsabila@mikroskil.ac.id
}

\begin{abstract}
Abstrak
Sistem yang terintegrasi dalam manajemen sumber daya manusia sangat diperlukan perusahaan sehingga adanya kebutuhan untuk mengelola kehadiran karyawan dengan lebih baik dan kebutuhan dalam pengambilan keputusan yang lebih tepat mengenai penerimaan karyawan baru, penilaian karyawan, penempatan posisi, pelatihan karyawan, dinas karyawan, dan pemberhentian karyawan. Karena kebutuhan tersebut maka diperlukan sebuah sistem yang terintegrasi dalam menangani proses kehadiran sampai pemberhentian karyawan. Sehingga dapat membantu perusahaan dalam melakukan pengelolaan data kehadiran karyawan yang lebih baik dengan meminimalisir terjadinya kecurangan, mengurangi penggunaan kertas dan menghemat waktu pekerjaan bagian SDM dalam merekap kehadiran dan membantu manajer SDM dalam mengambil keputusan yang lebih tepat berkaitan dengan proses yang ada diperusahaan seperti membantu dalam menentukan karyawan yang lebih tepat menempati posisi berdasarkan kualifikasi posisi dengan kemampuan yang dimiliki oleh karyawan. Pengembangan Sistem Informasi ini menggunakan metodologi System Development Lifecycle (SDLC) dimulai dengan merancang Fishbone Diagram, Data Flow Diagram (DFD), Diagram PIECES, rancangan antarmuka sistem, Microsoft Visual Studio 2012 sebagai data masukan, Microsoft SQL Server 2012 sebagai media penyimpanan data dan SAP Crystal Reports sebagai masukan keluaran berupa laporan. Penulis berharap, hasil dari pengembangan sistem informasi ini dapat membantu perusahaan menangani masalah yang ada dalam manajemen sumber daya manusia.
\end{abstract}

Kata Kunci: Manajemen Sumber Daya Manusia, kehadiran, SDLC, Sistem Informasi

\begin{abstract}
A human resource management is an integrated system important to a company, resulting in a need for better employee attendance and the need for more informed decision-making regarding new employee recruitment management, employee appraisal, position placement, employee training, employee service, and employee dismissal. Because of these, an integrated system is needed in handling the attendance process until the employee termination. So as to meet the needs of the company in the management of data attendance of employees better by minimizing the occurrence of fault, reduce paper use and worktime of HR department in attendance recording and help HR managers on making more appropriate decisions related to existing processes in company such as helping on determining appropriate employees occupy positions based on position qualification with the employee ability. This Information System Development using System Development Lifecycle methodology (SDLC) begin with designing Fishbone Diagram, Data Flow Diagram (DFD), PIECES Diagram, system interface design, Microsoft Visual Studio 2012 as input, Microsoft SQL Server 2012 as data storage and SAP Crystal Reports as output in reports. The authors hope, the results of this information system development can help companies to deal with existing problems in human resource management.
\end{abstract}

Keywords: Human Resources Management, Attendance, SDLC, System Information

\section{PENDAHULUAN}

Pada umumnya pengelolaan kehadiran karyawan yang masih menggunakan cara konversional dengan mencatat kehadiran karyawan pada kertas secara manual menyebabkan banyaknya penggunaan kertas, prosesnya juga memakan waktu yang cukup lama, dan biasanya rentan terjadinya kecurangan, seperti karyawan yang terlambat tetapi karyawan masih dapat membuat kehadirannya sesuai dengan jam kerja yang telah ditetapkan oleh perusahaan, selain itu bagian SDM membutuhkan waktu lama dalam merekap kehadiran karyawan dikarenakan data karyawan yang banyak. Sehingga adanya kebutuhan untuk mengelola kehadiran dengan lebih baik.

Adanya kebutuhan dalam pengambilan keputusan yang lebih tepat mengenai penerimaan karyawan baru, penilaian karyawan, penempatan posisikaryawan, pelatihan karyawan, dinas karyawan dan pemberhentian karyawan karena dalam pengambilan keputusan manajer SDM hanya mengambil keputusan berdasarkan hal yang kurang tepat, misalnya dalam pemindahan posisi karyawan, manajer SDM hanya melihat karyawan berdasarkan kinerja karyawan padahal seharusnya ada banyak ketentuan-ketentuan yang dapat dihasilkan untuk melakukan pemindahan posisi kerja dari karyawan seperti tanggung jawab karyawan dalam bekerja, displin karyawan, kemampuan kerjasama karyawan dan membandingkan kompetensi yang dimiliki karyawan dengan kualifikasi posisi.

Berdasarkan latar belakang masalah tersebut, maka pada bagian selanjutnya akan dibahas mengenai kajian pustaka yang berhubungan dengan sistem informasi dan manajemen sumber daya manusia.

Sistem informasi adalah sistem yang digunakan dalam organisasi yang mempertemukan kebutuhan pengelolaan transaksi harian yang mendukung fungsi operasi organisasi yang bersifat manajerial dengan kegiatan strategi dari suatu organisasi untuk dapat menyediakan kepada pihak luar laporan-laporan yang diperlukan [1].

Manajemen Sumber Daya Manusia adalah mengelola sumber daya manusia. Dari keseluruhan sumber daya yang tersedia dalam suatu organisasi, baik organisasi publik maupun organisasi swasta, sumber daya manusia yang paling penting dan sangat menentukan. Sumber daya manusia merupakan satu-satunya sumber daya yang memiliki akal, perasaan, keinginan, kemampuan, keterampilan, pengetahuan, dorongan, daya dan karya. Semua potensi 
sumber daya manusia tersebut sangat berpengaruh terhadap upaya organisasi dalam pencapaian tujuan organisasi [2].

\section{METODE PENELITIAN}

\subsection{Evaluasi Heuristic}

Metodologi penelitian pengembangan sistem dilakukan dengan menggunakan System Development Life Cycle (SDLC). Terdapat tujuh tahapan dalam metodologi SDLC, namun penulis hanya melakukan sampai pada tahapan kelima, dimana tahapan-tahapan tersebut yakni:

1. Mengidentifikasi Masalah, Peluang dan Tujuan

Pada tahap ini, proses identifikasi masalah menggunakan fishbone diagram (diagram tulang ikan)

a. Adanya kebutuhkan untuk mengelola kehadiran karyawan dengan lebih baik.

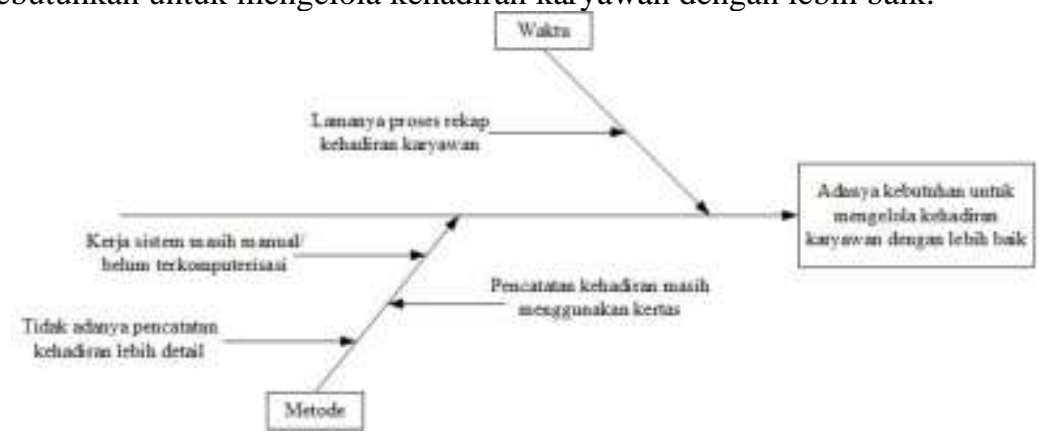

Gambar 1. Kebutuhkan pengelolaan kehadiran karyawan

b. Adanya kebutuhkan dalam pengambilan keputusan yang lebih tepat mengenai penerimaan karyawan baru, penilaian karyawan, penempatan posisi, pelatihan karyawan, dinas karyawan dan pemberhentian karyawan.

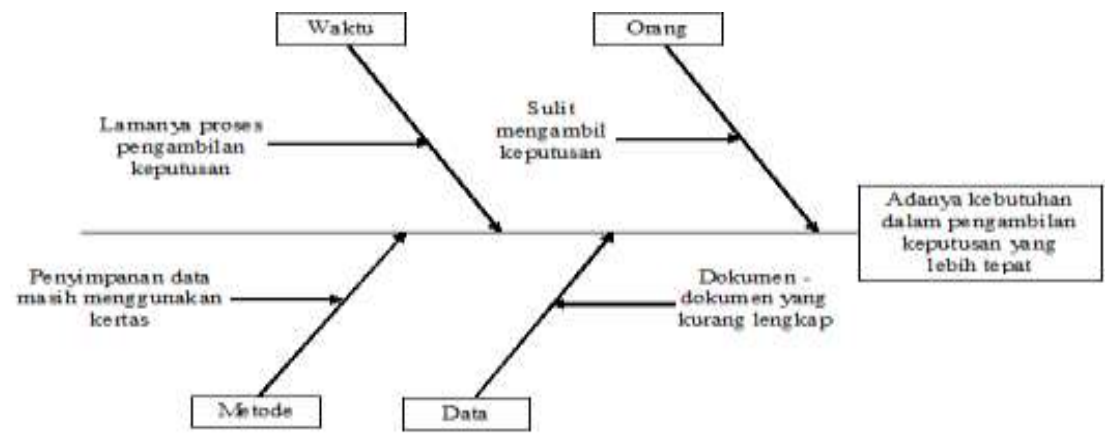

Gambar 2. Kebutuhan dalam pengambilan keputusan

Berdasarkan dari masalah diatas maka penulis merancang sistem baru yang menjadi peluang untuk memecahkan masalah tersebut yaitu untuk membantu perusahaan dalam mengelola data kehadiran karyawan dengan lebih baik dan membantu manajer SDM dalam mengambil keputusan yang lebih tepat mengenai penerimaan karyawan baru, penilaian karyawan, penempatan posisi, pelatihan karyawan, dinas karyawan dan pemberhentian karyawan. Dengan tujuan untuk mengembangkan sistem informasi manajemen sumber daya manusia yang saling terintegrasi.

2. Menentukan Syarat-Syarat Informasi

Pada tahap ini aktivitas yang dilakukan yaitu untuk pengumpulan informasi untuk melakukan proses pengelolaan sumber daya manusia. Adapun beberapa teknik pengumpulan data yaitu :

a. Studi Pustaka

Dalam membantu analisis dan perancangan sistem, penulisan juga menggunakan sumber-sumber referensi seperti buku-buku yang berkaitan dengan topik manajemen sumber daya manusia dan bahan bacaan lainnya.

b. Observasi

Pengumpulan data dengan cara mendapatkan informasi secara langsung terhadap sistem OrangeHRM dengan mencatat hal-hal penting yang berhubungan dengan Sistem Manajemen Sumber Daya Manusia agar mendapatkan informasi yang lengkap dan akurat.

Selain mengumpulkan informasi, dalam tahap ini penulis juga menggambarkan data flow diagram untuk sistem berjalan. Berikut adalah rancangan diagram konteks dan diagram level 0 dari sistem berjalan: 


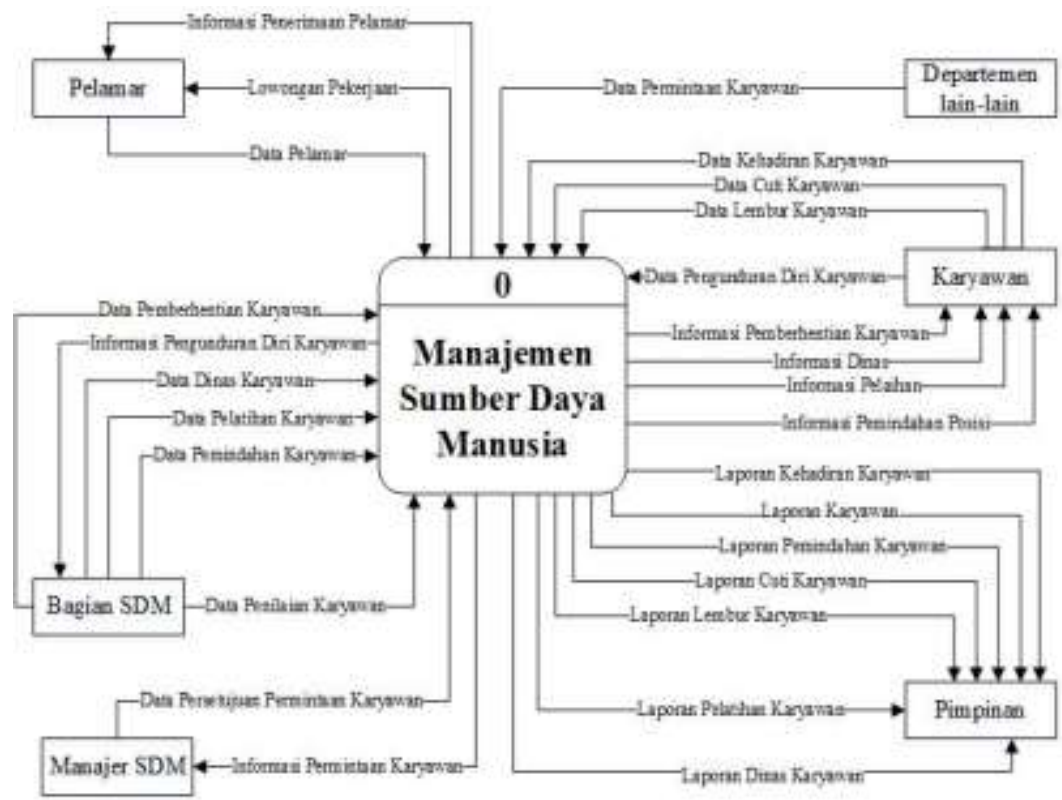

Gambar 3. DFD Konteks Sistem Berjalan

3. Menganalisis Kebutuhan-Kebutuhan Sistem

Kebutuhan fungsional akan digambarkan dengan menggunakan use case diagram. Adapun actor didalamm use case diagram dibagi menjadi 5 macam yang terdiri dari karyawan, manajer bagian, manajer SDM, bagian SDM, dan pimpinan yang memiliki hak akses masing-masing. Adapun gambaran use case diagram Sistem Informasi Manajemen Sumber Daya Manusia sebagai berikut.

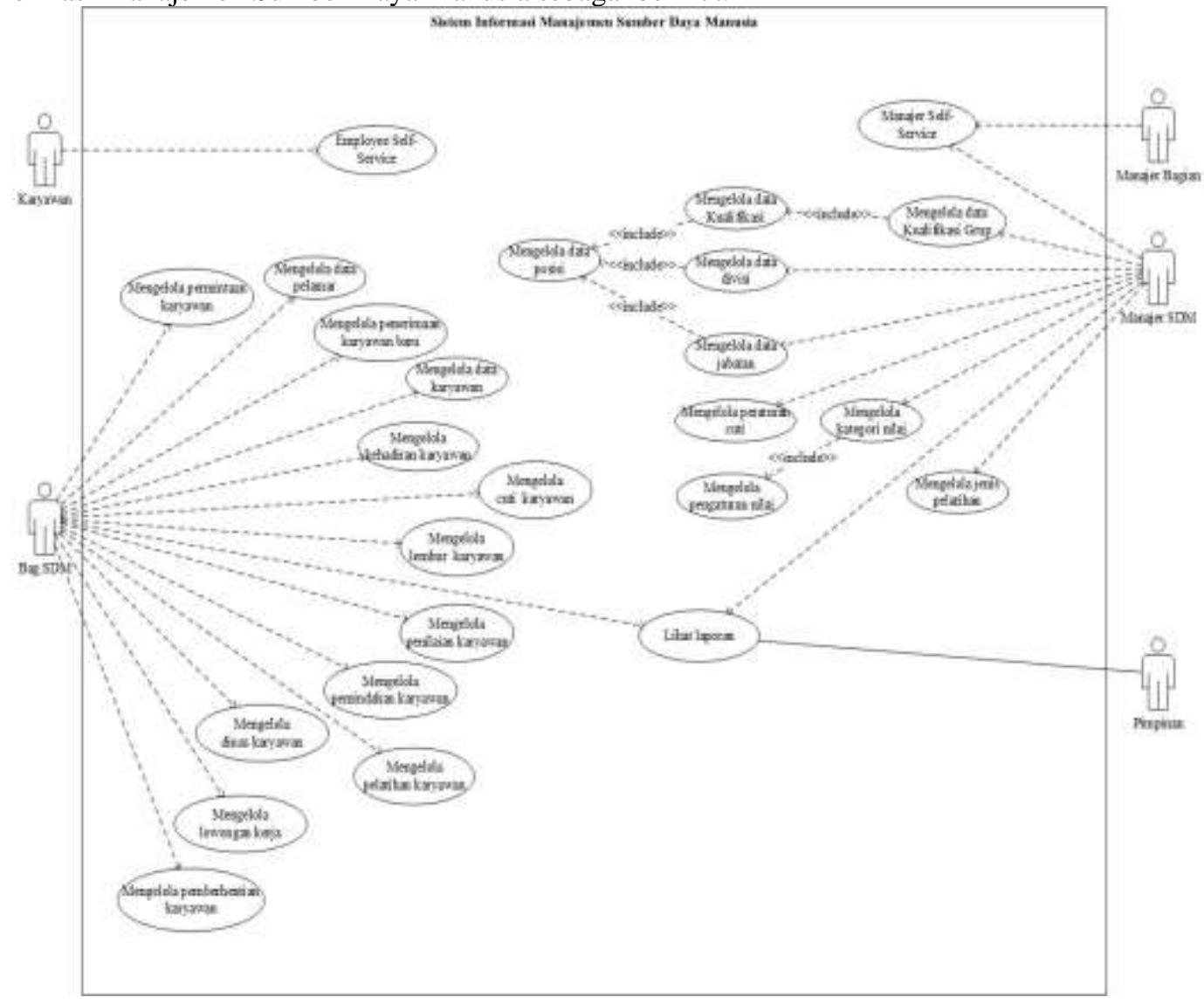

Gambar 4. Use-Case Sistem Infromasi Manajemen Sumber Daya Manusia

4. Merancang Sistem yang Direkomendasikan

Kegiatan yang dilakukan pada tahapan ini adalah:

a. Membuat Rancangan Proses

Pada tahapan ini, penulis merancang rancangan proses menggunakan Data Flow Diagram (DFD). Berikut adalah rancangan diagram konteks dan diagram level 0 dari sistem usulan: 


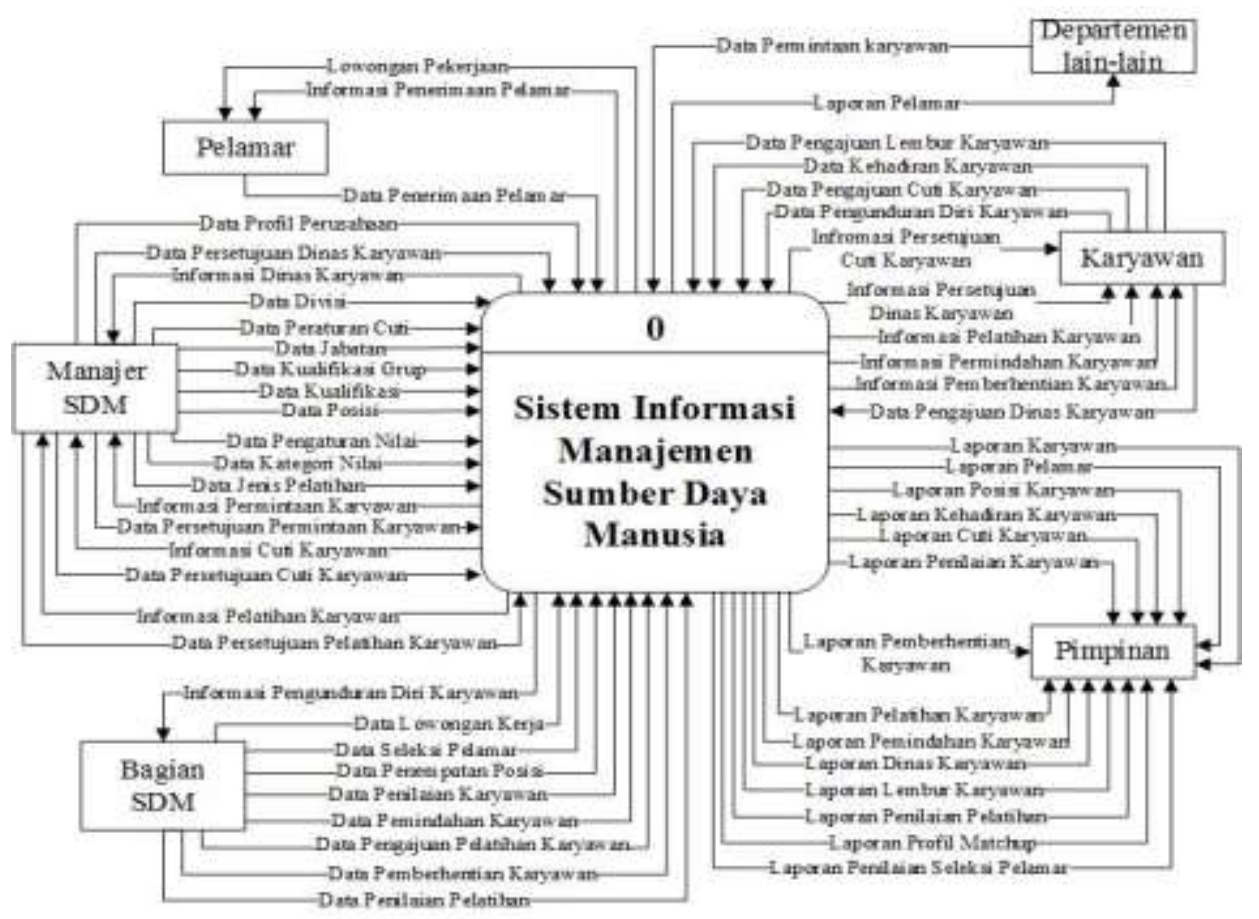

Gambar 5. DFD Konteks Sistem Usulan

b. Membuat Rancangan User Interface

Pada tahapan ini, penulis merancang tampilan sistem seperti tampilan Employee Self-Service, Manager Self-Service, form input, dan form output. Rancangan user interface didesain dengan menggunakan Microsoft Visual Studio 2012 dan SAP Crystal Reports

c. Membuat Rancangan Basis Data

Pada tahapan ini, penulis merancang basis data yang meliputi normalisasi, struktur table dan relasi antar tabel dengan menggunakan basis data Microsoft SQL Server.

5. Mengembangkan dan Mendokumentasikan Perangkat Lunak

Setelah hasil rancangan sistem maka selanjutnya pengembangan dilakukan dengan menggunakan bahasa pemograman desktop VB yang dikoneksikan dengan DBMS Microsoft SQL Server.

\section{ANALISA DAN PEMBAHASAN}

Hasil pengembangan Sistem Informasi Manajemen Sumber Daya Manusia dibagi menjadi 3 (tiga) bagian, yaitu bagian menu utama karyawan atau Employee Self-Service (ESS), menu utama manajer atau Manager Self-Service (MSS) dan menu utama admin. Menu utama karyawan merupakan menu yang hanya dapat diakses oleh karyawan.Menu utama manajer merupakan menu yang hanya dapat diakses oleh manajer, sedangkan menu utama admin merupakan menu yang hanya dapat diakses oleh admin.

Untuk masuk ke sistem, pengguna harus memiliki user yang telah di daftarkan admin sesuai dengan posisi yang ditempatkannya. Pengguna harus mengisi kode karyawan sebagai user id dan kata sandi. Apabila data benar maka sistem akan mengecek terlebih dahulu pengguna tersebut login sebagai karyawan, manajer atau admin.

Pada menu utama karyawan atau Employee Self-Service (ESS), karyawan dapat mengelola sebagian informasi profil diri sendiri, melihat riwayat posisi, kehadiran, dan karyawan juga dapat melakukan pengajuan lembur dan pengajuan cuti.

Pada menu utama manajer atau Manager Self-Service (MSS), manajer dapat mengelola sebagian informasi profil diri sendiri, melihat riwayat posisi, kehadiran, dapat mengelola pengajuan permintaan karyawan, pengajuan lembur, pengajuan cuti, pengajuan dinas, pengajuan pelatihan, dapat mengelola persetujuan cuti, persetujuan dinas, dan dapat melihat beberapa laporan. Sedangkan pada menu admin, admin dapat mengelola semua informasi yang ada di dalam sistem, mulai dari data master, data transaksi, laporan dan mengelola pengaturan..

\section{KESIMPULAN}

Adapun kesimpulan yang dapat disampaikan adalah:

1. Dengan pengembangan sistem informasi manajemen sumber daya manusia ini diharapkan dapat memenuhi kebutuhan untuk mengelola kehadiran karyawan dengan lebih baik agar dapat meminimalisir terjadinya kecurangan, mengurangi penggunaan kertas karena data telah tersimpan ke database sistem dan menghemat waktu pekerjaan bagian SDM dalam merekap kehadiran karyawan. 
2. Sistem yang dikembangkan dapat memberikan informasi yang sesuai dengan kebutuhan dalam pengambilan keputusan yang lebih tepat mengenai penerimaan karyawan baru, penilaian karyawan, penempatan posisi, pelatihan karyawan, dinas karyawan dan pemberhentian karyawan, seperti informasi yang lebih tepat dalam menempatkan posisi karyawan berdasarkan kualifikasi posisi dengan kompetensi yang dimiliki karyawan sehingga perusahaan di tuntut perlu mengembangkan sistem informasi manajemen sumber daya manusia yang terintegrasi.

\section{REFERENCES}

[1] Tata, S., 2012, Konsep Sistem Informasi, Yogyakarta, ANDI.

[2] S. Gomes, 2003, Manajemen Sumber Daya Manusia, Yogyakarta, ANDI.

[3] J Hutahaean, 2015, Konsep Sistem Informasi, Deepublish

[4] J Simarmata, 2007, Perancangan Basis Data, ANDI

[5] J L Whitten, 2003, System Analysis and Design Methods, McGraw-Hill 